ISSN 1981-416X

Licenciado sob uma Licença Creative Commons

(c) (1)

\title{
Ateliê Didático: diário online e pesquisa- formação com docentes universitários
}

\author{
"Ateliê Didático": online diary and research training with \\ university professors
}

\section{"Ateliê Didático": diario online e investigación-formación com los docentes universitarios}

\author{
Cristina d'Ávila ${ }^{[a]}$, Ana Verena Madeira ${ }^{[b]}$, Denise Guerra ${ }^{[c]^{*}}$ \\ [a] Universidade Federal da Bahia (FACED), Salvador, BA, Brasil \\ [b] Universidade Federal da Bahia (IBIO), Salvador, BA, Brasil \\ [c] Universidade Federal da Bahia (FACED), Salvador, BA, Brasil
}

\section{Resumo}

O Ateliê Didático surge no bojo do Programa de Formação Pedagógica de docentes universitários (ForPed) na Universidade Federal da Bahia e constitui-se em dispositivo formativo presencial e online e de pesquisa-formação, pautado em três pilares fundamentais:

CD: Doutora, e-mail: cristdavila@gmail.com

AVM: Doutora, e-mail: madeira@ufba.br

DG: Doutora, e-mail: demouj@gmail.com 
epistemologia da prática, dimensão sensível e fazer criativo, possibilitando aos participantes a abordagem e vivência de conceitos didático-pedagógicos básicos relativos à educação superior (ES), o estudo do objeto e saberes da docência e da construção da identidade profissional do docente universitário, análise das relações entre currículo, e formação, debate sobre abordagens pedagógicas na ES, compreensão das relações estruturantes do processo didático, reflexões sobre as relações interpessoais e organização da prática pedagógica. Na sua dinâmica metodológica prevê-se os diários online, a partir dos quais revelam-se os dados da presente pesquisa-formação, na qual os docentes descrevem suas implicações com a docência, saberes didático-pedagógicos e com os estudantes. Participaram da pesquisa, de caráter qualitativo, por adesão voluntária, nove docentes universitários. Destarte, o Ateliê tem se revelado dispositivo aberto para alterar e ser alterado pela práxis dos sujeitos em formação conforme depreendido dos diários online produzidos e analisados.

Palavras-chave: Formação Pedagógica. Docente universitário. Implicação. Diários online.

\begin{abstract}
The "Ateliê Didático" is part of the pedagogical training program for university teachers (Forped) at the Federal University of Bahia. It is an online and in-person training and research training device based on three fundamental pillars: epistemology of practice, creative production, and sensitive training. The participants address fundamental concepts in higher education (HE): study of the object and knowledge of teaching in UE and the construction of professional identity of university professor; analysis of the relationship between curriculum and training; debate on pedagogical approaches in UE; understanding of the structuring relationships of the didactic process; reflections on interpersonal relations and organization of pedagogical practice. In its methodological dynamics, online training journals are envisaged, from which the data of the present research training are revealed, in which teachers describe their involvement with teaching, didactic-pedagogical knowledge, and students. Nine university professors participated voluntarily in the qualitative research. Thus, the Ateliê has proved to be a device open to altering and being altered
\end{abstract}


by the praxis of the subjects in training, as understood from the produced and analyzed training journals.

Keywords: Pedagogical Training. University Teachers. Involvement. Online Journal.

\section{Resumen}

El "Ateliê Didático" surge en el seno del Programa de Formación Pedagógica de docentes universitarios (ForPed) en la Universidad Federal de Bahía y se constituye un dispositivo formativo presencial y online y de investigación-formación, pautado en tres pilares fundamentales: epistemología de la práctica, dimensión sensible y poiésis. Aborda conceptos fundamentales como la análisis de las relaciones entre el currículo y la formación, debate sobre enfoques pedagógicos en la educación superior (ES), el estudio del objeto y los saberes de la docencia y de la construcción de la identidad profesional del docente universitario, comprensión de las relaciones estructurantes del proceso didáctico, reflexiones sobre las relaciones interpersonales y organización de la práctica pedagógica en la ES. En su dinámica metodológica se prevén los diarios de formación online, a partir de los cuales se revelan los datos de la presente investigación-formación, en la cual los docentes describen sus implicaciones con la docencia, saber didáctico-pedagógico y con los estudiantes. Participaron de la investigación, de carácter cualitativo, por adhesión voluntaria, nueve docentes universitarios. De este modo, el "Ateliê" se ha revelado dispositivo para alterar y ser alterado por la praxis de los sujetos en formación conforme inferido de los diarios de formación producidos y analizados.

Keywords: Formación pedagógica. Docente universitario. Implicación. Diarios online.

\section{Introdução}

A literatura contemporânea tem apontado para a busca da ressignificação da profissionalidade docente, no sentido da autonomia e da 
reflexão associada, inclusive, a um redimensionamento dos processos formativos. As políticas de admissão e de progressão de carreira na universidade priorizam os títulos em detrimento da experiência progressiva, valorização da especialização nos saberes específicos de dada área e sem exigência de qualquer formação pedagógica, caracterizando os docentes como "práticos", portadores de saberes provenientes do senso comum e reprodutores de suas experiências como estudantes (CUNHA, 2010; LEITE; RAMOS, 2010).

As propostas para a formação de professores das Instituições de Ensino Superior (IES), em diversos países, incluem, historicamente: 1) a realização de cursos de pós-graduação lato sensu; 2) a inclusão de disciplinas educacionais nos mestrados e doutorados e 3) a realização de estágio de docência nestes cursos. No entanto, poucas pesquisas deram conta de investigar se, e como essas iniciativas alteraram o quadro da profissionalização dessa docência. A relevância das IES assumirem a promoção de ações de formação em serviço vem sendo destacada, bem como a necessidade do caráter de continuidade das mesmas para criação de uma cultura institucional (ALTHAUS, 2016; BEHRENS, 2010; CUNHA, 2010).

Os cursos de pós-graduação, apontados desde a Lei de Diretrizes e Bases de 1996 (BRASIL, 1996) como lócus de formação do professor universitário, ainda priorizam o desenvolvimento de conhecimentos teóricos e instrumentais, da atividade de pesquisa e de produção de conhecimento, com apropriações referentes ao campo científico de atuação (ALMEIDA; PIMENTA, 2014; D’ÁVILA, 2013). Em geral, não incluem discussões sobre aspectos pedagógicos, desconsiderando que os elementos-chave do processo de investigação (sujeitos envolvidos, tempo, conhecimento, resultados e métodos) não são os mesmos necessários à atividade de ensinar (PIMENTA; ANASTASIOU, 2010).

Dessa maneira, "a graduação tem sido 'alimentada' por docentes titulados, porém, sem a menor competência pedagógica" (VASCONCELOS, 1998, p. 86). O professor universitário entra na profissão sem uma reflexão sobre a educação e desconhecendo cientificamente os elementos constitutivos da própria ação docente. Porém, uma formação pedagógica 
é cada vez mais exigida, seja em função do movimento de profissionalização da docência, seja frente às mudanças do cenário sociocultural internacional que vêm repercutindo na própria constituição das Instituições de Ensino Superior (IES) (CUNHA, 2010; LEITE; RAMOS, 2010 e 2012).

Neste cenário, um novo programa de formação pedagógica docente (ForPed) foi gestado na Universidade Federal da Bahia, e nele se incluíram os ateliês didáticos, como dispositivo de formação docente e de pesquisa. Na pesquisa-formação que ora apresentamos, optamos por uma abordagem que além de caracterizar as atividades formativas dos docentes universitários participantes do programa, busca desvelar as implicações destes docentes a partir de suas narrativas em diários online.

Na perspectiva da educação online — "modalidade de educação que pode ser vivenciada ou exercitada tanto para potencializar situações de aprendizagem mediadas por encontros presenciais, quanto a distância [...]; ou ainda situações híbridas, mediados por tecnologias telemáticas (SANTOS, WEBER, s/d, p. 3)" — os diários online funcionaram como importante dispositivo de formação e de pesquisa no bojo do Ateliê didático, a partir do ambiente virtual de aprendizagem (AVA) Moodle. O dispositivo alocado nesta plataforma possibilitou aos cursistas uma escrita implicada, além de disparar um processo metacognitivo sobre suas práxis, desde o primeiro dia de aula. Como afirma SANTOS e WEBER (2013, p. 290) "os ambientes virtuais de aprendizagem (AVAs) são os meios telemáticos mais utilizados para as práticas de educação online encontradas no ciberespaço, hoje potencializados pela mobilidade, permitindo que o acesso aos ambientes não se dê de forma fixa, presa a um desktop". Ressalte-se o quanto essa prerrogativa permitiu aos cursistas e às formadoras maior assertividade na condução e organização dos trabalhos.

Nesse sentido, durante a ação formativa em tela, propusemos aos professores universitários que desenvolvessem seus diários de formação online. Estas produções constituíram potentes dispositivos de investigação dos processos implicacionais dos professores na sua formação para a docência. Para Macedo (2010), o termo implicação teve origem no verbo "plicare" (dobrar-se) e constitui uma relação ideológica com a realidade 
social na qual estamos imersos. Supõe um sujeito que tem o manejo de estratégias da realidade, como também, uma ação sobre elas a partir da reflexão e construção de seus etnométodos ${ }^{1}$.

A partir da análise dos diários online de professores participantes do Ateliê Didático, buscamos compreender de que modo foram mobilizadas as implicações destes professores e a ressignificação de sua práxis na formação pedagógica para a docência.

\section{Descrevendo o ateliê didático}

O Ateliê Didático surge no bojo do Programa de formação docente continuada - o Forped. Criado como dispositivo de formação - curso teórico-prático semipresencial — o ateliê vai além de um curso de 40 horas e constitui um poderoso dispositivo de pesquisa-formação capaz de possibilitar aos docentes universitários implicados a conscientização de sua condição de profissionais professores comprometidos com seu que fazer cotidiano.

O ateliê teve seu início no ano de 2016, tendo levado o ano anterior na sua gestação. O nome ateliê provém do francês atelier e significa lugar de criação, por isso a sua escolha. Na nossa cultura, normalmente, espaço destinado à criação artística. As cinco turmas iniciais do "Ateliê Didático", em 2016 e 2017, foram constituídas por docentes universitários de diversas áreas e com diferentes tempos de serviço na instituição. A coordenação e mediação foi feita por docentes da própria Universidade.

Assumimos como pilares fundamentais na concepção dos ateliês (D’ÁVILA, 2016): 1) a epistemologia da prática, pois acredita-se que é a partir dos saberes da experiência que se transformam paradigmas e se aprende de modo significativo; 2) a dimensão sensível, da qual fazem parte as múltiplas linguagens artísticas; 3) a poéisis ou o fazer criativo.

1 [...] maneiras pelas quais as pessoas na vida cotidiana, com seus saberes e formas de aprender, suas integibilidades, suas descritibilidades e analisibilidades, constroem a vida cotidiana, compreendem o mundo e resolvem seus problemas no dia-a-dia (MACEDO, 2010, p. 54). 
Assim, engendramos uma formação em que saberes da prática docente são ressignificados em saberes da práxis e em que o teor didático e pedagógico desses saberes são apreendidos com consciência pelos participantes, levando-os a repensar e a reestruturar sua práxis pedagógica.

Assim, os ateliês no processo formativo dos professores visam: buscar nas trajetórias pessoais dos docentes, os traços que influenciaram e influenciam a escolha da profissão como professores(as) universitários(as); evidenciar compreensão sobre o papel do professor universitário frente aos desafios da sociedade do conhecimento: seus dilemas, sua identidade e profissionalidade; conhecer abordagens pedagógicas relacionadas ao ensino superior; compreender os processos de aprendizagem do público adulto, adequando-se às suas necessidades sócio-afetivas e características cognitivas; conhecer e analisar os tipos e etapas de planejamento de ensino numa perspectiva dialética e crítica; operacionalizar o planejamento didático no espaço da sala de aula, redimensionando suas experiências com vistas à exercitação da prática pedagógica no ensino superior.

Nas modalidades presencial (30h) e a distância (10h), este dispositivo de formação e de pesquisa-formação vem sendo desenvolvido de forma interativa, possibilitando aos participantes a abordagem e vivência de conceitos didático-pedagógicos básicos, com base em atividades adequadas à educação universitária. O trabalho desenvolvido à distância, online, proporciona aos docentes em curso o desenvolvimento de diversas atividades inclusive a ressignificação dos seus planos de ensino-aprendizagem advindos de suas práticas docentes, tendo como suporte as leituras e estudos realizados no módulo presencial. Usamos para este fim o ambiente Moodle e/ou as redes sociais. No processo do curso, a avaliação é entendida como uma constante. O Diário formativo online é adotado por adesão voluntária, e tem trazido elementos que favorecem nossa compreensão sobre como estes docentes se implicam em seus processos formativos ao longo do curso.

Desconfiamos que, em consonância ao pensamento de Bakhtin, o Ateliê Didático, vem se revelando dispositivo para alterar e ser alterado pela práxis curricular e formativa dos docentes em formação (MACEDO, 2011). 
Assim, nos instigamos a investigar se, e como se dão os processos implicacionais desses docentes ao longo da formação através da análise dos seus diários de formação.

\section{A composição metodológica da pesquisa e o desenho dos Diários de formação}

A opção metodológica da pesquisa qualitativa sustentou-se nos diários online como instrumento de produção de informação, valorizando as narrativas dos sujeitos em formação, na análise das informações pela técnica de análise de conteúdos (BARDIN, 2011) e no movimento interpretativo mobilizado e pautado por uma hermenêutica intercrítica. Assim, nove professores cursistas, com uma densidade prática e reflexiva sobre a temática Formação do Docente Universitário, foram convidados a participar da pesquisa.

A escrita dos diários online se vincula à explicitação e à compreensão da experiência formativa e do processo instituinte curricular, a partir da tomada de decisão da pessoa sobre sua formação. O sujeito se autoriza a fazer a si mesmo ator/autor, pesquisadores de si. Decide o que fazer e com que meios (MACEDO, 2013). O autorizar-se a narrar a própria formação implica numa ação concreta, intencional que permite a autorreferência, bem como os hibridismos, as múltiplas referências, a valoração e a avaliação do que é considerado formativo.

O diário online, como dispositivo pedagógico de aprendizagem e de pesquisa-formação, se constitui em narrativas reflexivas das experiências subjetivas no processo formativo do ator social, em potência, protagonista, autor da sua construção, da sua itinerância. Segundo Guerra (2014), a experiência das narrativas, por meio dos diários, amplia o desejo, a iniciativa, o hábito, a habilidade, o rigor de escrever, provoca ressonâncias permanentes nas ações cotidianas. Além disso, proporciona o compartilhamento das experiências e mudanças mais cooperativas no trabalho, contribui para a perspectiva de avaliação pautada no acompanhamento e coorientação na qual negociação, responsabilização, 
autonomização, intercompreensão concretizam a avaliação na formação, explicitada na obra de Macedo (2010), e se compatibiliza com outras modalidades didáticas, a exemplo dos memoriais e portfólios.

A prática pedagógica com uso dos diários não é nova, porém o suporte digital concedeu a esta modalidade de trabalho formativo e investigativo um outro status, permitindo que o conteúdo do diário "seja compartilhado de forma síncrona ou assíncrona. Para interagir intervindo fisicamente na mensagem basta ter acesso a interface online. A prática do diarismo online é um fenômeno da cibercultura" (SANTOS, WEBER, s/d, p. 03).

Do ponto de vista metodológico, assumimos a configuração do diário de itinerância forjado por René Barbier na obra A Pesquisa-Ação que explicita como transformar um documento de caráter sigiloso, pessoal em dispositivo de partilha, de formação. Segundo Barbier (2004), o diário de itinerância é um instrumento de investigação sobre si mesmo em relação ao grupo e em que se emprega a tríplice escuta/palavra - clínica, filosófica e poética — da abordagem transversal.

O diário de formação no Ateliê Didático se constituiu numa grafia possível da formação experienciada e materializada no texto narrado por cada professor. Uma tessitura delicada que, em potência, transforma o narrador, sua prática docente e vida humana. Nosso papel na construção dessa obra inédita foi de ouvinte, que acompanha. No processo de categorização, como base no "Tema", foram reagrupados os elementos dos textos (indicadores), segundo analogias semânticas.

\section{Os diários de formação: as inquietações e provocações do ateliê didático}

Da nossa escuta sensível sobre os diários online dos cursistas do Ateliê Didático explicitamos as ideias agrupadas como: 1) implicações e demandas dos docentes para com a própria formatividade; 2) implicações com a docência, no que se refere à identificação com a docência, mas 
também no que se refere às suas práticas; 3) implicações com saberes didáticos-pedagógicos e 4) implicações com o estudante.

Além disso, a leitura autorizada dos diários online dos professores nos possibilitou perceber que a prática docente destes está relacionada aos dilemas e aos processos deliberativos gerados a partir dessas situações dilemáticas, sobre as quais nem sempre tem clareza e que surgem como acontecimentos, imprevisibilidades sujeitas à necessidade de construir decisões imediatas.

\section{Implicações e demandas dos docentes para com o próprio processo formativo}

Os professores expressaram diversas questões como o valor da coletividade e da diversidade de pensamentos nos processos formativos.

[...] sobre as discussões das mandalas, [...] me peguei recordando dos depoimentos que mais me impactaram. Identifiquei muito com a amorosidade expressa na mandala de uma colega da medicina veterinária que trouxe elementos figurados da natureza constituindo sua trajetória e centrados no seu objeto de estudo com suínos, denotando amor ao que faz e cuidado como animal foco de sua atenção. Lembrei também do pragmatismo de alguns colegas, que instintivamente me despertou interesse pela lógica de seu raciocínio, mas me chocou por certa falta de emoção sob minha ótica. Engraçado como quando estamos em grupo buscamos afinidades e identidades de conceitos pré-formatados e concepções... Olha aí o convite ao desarmamento e reconstrução? [...] (Professor 1).

A diversidade de pensamentos e práticas explicitados hoje tornaram o ambiente mais agradável e desafiador. Agradável e alentador porque dá a sensação de que estamos juntos com necessidades e questões semelhantes, diante de pessoas capacitadas para mediar e trazer novas soluções para essas questões... (Professor 8 ).

Também destacam a importância, as barreiras e motivações do próprio investimento na sua formação como docente e compreendem que a 
formação inicial não é o único espaçotempo ${ }^{2}$ de aprendizagem da docência, legitimando as possibilidades de formação continuada, como o Ateliê Didático.

Vim para o Ateliê Didático justamente para estreitar laços com aqueles que estão envolvidos neste tipo de processo formativo na UFBA, visando amadurecer novos projetos, incrementar o curso já em andamento e refletir sobre a possibilidade de um doutorado em Educação. A vivência de ontem com a 'Dinâmica de Rede', representou exatamente o que vim buscar: novas conexões e acolhimento dentro da UFBA para essa demanda que é não só pessoal como coletiva, vez que minha função hoje trouxe novos horizontes e muitas responsabilidades. [...] Enfim, muito o que aprender! (Professor 1).

Aos 37 anos de serviço me sinto desafiada a continuar contribuindo por mais um tempo. Comecei muito cedo jogada numa sala de aula aos 21 ANOS. Somente agora ter a oportunidade de tentar consolidar e sistematizar questões de base. que maravilha está no Ateliê! Marcante esse dia para refletirmos sobre o ato de planejar, objetivos e conteúdos e o percurso metodológico (Professor 7).

Estou fazendo, dias depois, o estudo do que preciso, baixei o mapa conceitual e sigo tentando investir no que ficou pelo caminho nas duas semanas de curso. Vi a pertinência da minha inteireza quando fui chamada para comentário sobre a forma do meu diário e minha participação, mas não posso negar que foram décadas de investimento em terapia, autoconhecimento, formação, autoformação, ecoformação, muita implicação, empoderamento, idas e vindas (Professor 3).

Muitas situações descritas pelos docentes expressam seus contextos de vida durante a formação, o que contribui para reflexões e tomada de decisão sobre a emergência de novas aprendizagens.

2 Nilda Alves justifica que junta os termos espaço e tempo em uma única palavra em referência, no entendimento da autora, "à única possibilidade de existência desses termos - um tem relação com o outro e só existe nessa relação..." Alves, N. (2001). Imagens das escolas: sobre redes de conhecimentos e currículos escolares. Educar, n. 7, p. 53-62. 2001. 
Infelizmente não pude comparecer à atividade do dia 19/04. Mas, tive a oportunidade de assistir ao vídeo, assim como fazer a leitura dos textos. O texto do Prof. Macedo, muito denso, necessitaria de mais tempo e calma para uma melhor compreensão. De todo modo, aproximações aos 'atos de currículo', percebendo-os como algo inerente à nossa ação diária, foi muito interessante. Da mesma forma, a ideia da aprendizagem como fenômeno relacional e a noção de metaformação. Pensar sobre tais conceitos, nos remete a nosso fazer cotidiano, do estar em sala de aula, do planejar o curso, incluindo seus conteúdos, suas estratégias metodológicas, seus mecanismos de avaliação (Professor 2).

Nessa reflexão, como agente do processo de ensino-aprendizagem, revivi situações as mais diversas: questionando o processo de alfabetização de meu filho na educação infantil; participando de formação de trabalhadores da área da saúde numa perspectiva problematizadora; aprendendo um novo conceito na minha área específica, o qual me fez desconstruir uma concepção antiga e construir uma nova, com base em evidências científicas (Professor 2).

Em trabalho anterior, já havíamos identificado a valorização que os docentes universitários atribuem à experiência de coletividade como elemento importante na mudança de cultura institucional, favorecendo uma cultura de formação para a docência qualificada e implicada (MADEIRA, 2014).

Por outro lado, a implicação dos docentes do Ateliê Didático, em seus processos autoformativos, tem relação também com a concepção de formação adotada nesta ação. A palavra "formação" tem sido frequentemente usada para designar ações e iniciativas de desenvolvimento profissional, mas aqui tratamos como um conceito amplo e profundo, desenvolvido por diversos autores em uma teorização reflexiva do campo da formatividade (HONORÉ, 1980) ou de uma Teoria de Formação do "sujeito aprendente" no sentido dado por Josso (2004). Por muito tempo os processos e ofertas de educação direcionadas a adultos tiveram caráter aplicativo, totalitário e impositivo. Em contraposição, uma outra lógica formativa, baseada nos processos coletivos e colaborativos, como desenvolvido no Ateliê Didático, confere importância à experiência de quem 
aprende, em articulação com os contextos em que se desenrola a vida do sujeito aprendente.

Aliada à concepção de formação descrita, ressalte-se a concepção pedagógica que sustenta a prática pedagógica no ateliê. Uma concepção pedagógica raciovitalista, pela qual entende-se a razão aliada à sensibilidade e ao fazer criativo. É essa pertinência que dá solidez às aprendizagens no ateliê. O trabalho de mediação dos conteúdos dá-se numa perspectiva sensível, ludoartística (MAFFESOLI, 2005).

A arte ao integrar experiências sensoriais e sensíveis constitui matéria fundamental no currículo e dimensão integradora na educação como um todo. Toda obra artística, todo objeto artístico, seja um filme, uma tela ou uma música, irão integrar tais dimensões. Plena de significações, a obra de arte permite a educação do sensível mediante o contato sensorial e as abstrações. Como assevera Maffesoli, (D’ÁVILA, 2017, p. 1416): "Como o espírito do tempo destaca a criatividade então é preciso conseguir integrar pedagogicamente esta dimensão de poesia, de jogo. A expressão de Nietzsche que utilizo muitas vezes: "Fazer da própria vida uma obra de arte".

\section{Implicações com docência}

Há explicitação e reflexão dos professores sobre seu pensamento e dilemas básicos do campo profissional. Muitas das questões levantadas estão relacionadas com a própria prática.

Na discussão sobre matriz curricular feita no dia 19/04/2017, o perfil do egresso chamou muito a minha atenção por ser uma expectativa de vanguarda e muito alinhada com minha filosofia pessoal, crenças e valores utilizados como premissas, trazendo conforto no potencial de auxiliar os alunos a alcançarem essas metas através das atitudes do "modelo" que posso representar enquanto preceptora. Entretanto, percebemos um distanciamento entre as condições práticas de desenvolver métodos mais ativos em relação aos objetivos 
(ementa) e conteúdos postos no curriculum oficial da disciplina voltada ao internato (campo de prática preceptoral) (Professor 1).

Tivemos hoje uma exposição dialogada. [...] mais do que conhecer alguns modelos pedagógicos, a escuta atenta nos permitiu refletir sobre a nossa prática docente: como produzir nos nossos estudantes o desejo de aprender; como ensinar e como ensinar conteúdos eminentemente técnicos; como ser um mediador do conhecimento; como conciliar concepções pedagógicas e metodológicas com a rigidez do sistema institucional. E tantos outros dilemas e desafios. Essas e outras inquietações permanecerão. E temos a certeza que estamos num constante processo de aprendizagem a partir da reflexão-ação-reflexão da própria prática (Professor 2).

No último dia de curso, foi discutido sobre avaliação e enriqueceu muito a discussão em grupo onde os colegas expuseram suas estratégias avaliativas no cotidiano frente ás seus desafios junto a turmas numerosas e necessidade de atendimento a prazos curtos e conteúdos programáticos extensos e por vezes distante da aplicação pratica, desmotivando alunos (Professorestudante 1).

Um aspecto relevante abordado referiu-se à identificação destes participantes do Ateliê Didático com a ideia do "ser docente" no contexto da universidade, reforçando o processo de identidade profissional.

Ser docente é uma tarefa nobre e gratificante, porém muitas vezes árdua e desafiadora. Exige, de quem a abraça, uma constante predisposição para o novo, seja o conhecimento científico de sua área, seja o "novo" estudante que se nos apresenta, seja a necessária renovação do estar em sala de aula e lidar com novas tecnologias. A experiência já vivida até aqui traz algumas reflexões, dentre elas, destaca-se: a condição de ser docente, é também a de ser uma eterna aprendiz. [...] temos angústias, situações as mais diversas e desafios a compartilhar que nos anima a seguir em frente sabendo que não estamos sozinhos nessa caminhada. E o desejo explícito/implícito em muitas falas, de aprimoramento e de busca pelo exercício pleno da docência (Professor 2)

Ficou claro também que o objeto de trabalho do docente, professor, preceptor, tutor e todo aquele que se envolver no processo de ensino e aprendizagem éo ENSINO, exigindo da pessoa que ensina assumir um conteúdo expertise da 
profissão e a aquisição de habilidades e atitudes (COMPETÊNCIA PARA O ENSINO), desenvolvendo a consciência de ser um formador (Professor 1).

Muitos dilemas e reflexões dos docentes se relacionam com uma predominância dos saberes da prática na vida docente. Se por um lado isso pode produzir saberes próprios, criativos, autônomos e autorizantes, por outro a construção destes saberes, desprovidos de uma teoria e de uma reflexão sistemática geralmente significa a reprodução de práticas dos antigos docentes e uma prática formadora inócua.

Esse é um problema sério na formação de professores. A mobilização de saberes profissionais docentes, entenda-se saberes didático-pedagógicos, sem a devida consciência profissional, acarreta uma precarização no processo de construção das identidades profissionais, das profissionalidades e consequente profissionalismo docente. Os professores produzem e aprendem esses saberes. Defendemos que devam ser aprendidos, construídos e ressignificados nos cursos de formação inicial e continuada. Há, pois, nos ateliês didáticos, um espaço claro para a ressignificação desses saberes que brotam da experiência, mas também dos estudos, das teorias sobre o assunto. Os saberes didáticos, tais como, o planejar, o mediar, o acompanhar as aprendizagens dos educandos, o avaliar dentre outros saberes, são ensináveis nos ateliês junto à prerrogativa do envolvimento sensível às atividades. Então, não há aulas expositivas sobre estes saberes, há vivências práticas, sensoriais, com os mesmos, o que favorece, grandemente a sua ressignificação. Neste ponto, as atividades online praticadas no ambiente Moodle, como os fóruns e diários online, servem como importantes veículos para o pensar e compartilhar a prática desses saberes.

\section{Implicações com os saberes didático-pedagógicos}

Muitas das questões tratam do planejamento e muitas colocações remetem para as chamadas metodologias ativas e participativas. Alguns docentes/cursistas revelam quanto ainda estão aprisionados nas 
marcas epistemológicas das teorias e abordagens tradicionais, ao mesmo tempo em que anunciam a possibilidade generativa e criativa de teoria.

Percebi que várias técnicas didáticas que eu desenvolvia intuitivamente em sala (como leituras coletivas, passar filmes e músicas debatê-los, dramatização, trabalhos em duplas e grupos etc.) eram adequadas. Ao mesmo tempo, reparei em como eu estava aquém no que diz respeito ao planejamento e à avaliação. Sinto que o curso contribuiu para que eu me desenvolva enquanto docente e despertou ainda mais meu interesse pela didática (Professor 4).

Pela discussão do grupo de trabalho, pela fala dos colegas e pela exposição da aula de [docente-formadora E], comecei a reconstruir meus planos de aula, objetivos, conteúdos, minhas técnicas metodológicas... pensando nos alunos e suas e MINHAS possibilidades também. Estou bem feliz com as possibilidades/ferramentas pensadas. Agora é colocar em prática e ver se há um feedback positivo (Professor-estudante 5).

No segundo dia de atividades no Ateliê Didático, fomos convidados e compreender mais sobre o RACIOVITALISMO do Prof. Maffesoli, subsidiada pela teoria da RAZÃO SENSÍVEL, lendo os textos indicados e acompanhando a preleção e a linha de pesquisa-ação da Profa. [Docente formadora A], trazendo concepções acerca dos modelos pedagógicos vigentes e emergentes, destacando sua proposição chamada de Construcionista (abordagens crítico construtivas) - aprendizado significativo (apreensão inteligente e sensivel do conhecimento) levado à prática (POIÈSIS). Muitos conceitos já eram conhecidos em parte e me marcou mais a valorização do processo intuitivo como bagagem prévia e experienciada do aprendiz, que se mescla à razão lógica cientificista e a extrapola, quando ao contextualizar gera reflexão e convida a retornar à realidade (Professor-estudante 1).

Seguimos para o exercício de metodologia ativa em sala no presencial. Já havia lido os textos e preliminares, mas não as referências sobre PBL e Problematização e confesso aqui minha ignorância confusional, onde os conceitos estavam soltos e mal definidos de fato (Professor-estudante 1).

Novas técnicas/aprendizagens não vão acabar com nossos defeitos pessoais, mas certamente poderão contribuir para nos auxiliar a agir menos baseado nas nossas limitações, defeitos, inflexibilidades e/ou permissividades (Professor-estudante 8). 
O entusiasmo pelas metodologias de ensino caracterizadas como ativas e participativas foi um destaque nesse grupo do Ateliê. Se por um lado denota uma disposição para a mudança e a compreensão da necessidade de novas concepções sobre o sujeito aprendente e a função mediadora dos docentes, também pode remeter para a crença excessiva nos meios como salvadores do processo educativo. De qualquer forma, acreditamos que reflete a compreensão de que "[...] a docência na lógica tradicional não consegue possibilitar as relações necessárias para um ensino centrado na aprendizagem e no desenvolvimento da autonomia e de competência de intervenção dos estudantes" (LEITE; RAMOS, 2010, p. 29).

\section{Implicações com os estudantes}

Emerge o reconhecimento da importância de compreender a história/contexto do estudante da universidade na contemporaneidade, bem como seu perfil sociopolítico e cultural, considerando as políticas afirmativas da universidade. Destacaram-se também as preocupações com as questões de saúde mental e as reflexões sobre o perfil do egresso.

Com uma visão 'macro', acabamos por entender que é preciso derrubar burocracias e barreiras para que o ensino da UFBA volte a pulsar e estimular uma nova geração de alunos, com outras necessidades e desafios para estimular. 'Não cabem mais somente o quadro negro e o giz', como bem disse um colega participante da oficina (Professor-estudante 1).

Dia fundamental! Conheci o perfil do aluno UFBA e todas as modalidades de bolsa da instituição. Analisamos casos reais de situações com alunos com necessidades diferenciadas (Professor-estudante 6).

Aula muito esclarecedora da [formadora B]. Numa cidade em que temos uma maioria negra e considerando que temos uma quantidade significativa de alunos negros e/ou de baixa renda, o trabalho da PROAE [Pro-reitoria de Ações Afirmativas e Assistência Estudantil] é significativo na UFBA. No que se refere à currículo, precisamos também considerar tais números (Professor-estudante 9). 
Precisa haver um reconhecimento dos sujeitos envolvidos e das instituições como espaços de ensino. [...] Alice e o gato: 'para onde se quer ir?' Me remeto novamente ao perfil do egresso de meu curso. [...] existe uma criação da identidade docente por traz deste curso. Perfil admitido pela UFBA hoje $x$ necessidades atuais junto aos alunos com perfil cada vez mais plural. As chamadas metodologias emergentes se propõem a estimular ou somar esforços nesta busca de encantar pessoas com demandas distintas, reunidas num mesmo espaço de ensino e aprendizagem (Professor-estudante 1).

Ao final do processo formativo, convidamos cada professor a continuar falando de si, como uma busca para compreender as experiências de formação/profissionalização e da prática docente que deixam marcas nos tornando o professor que somos hoje.

\section{Considerações finais}

\section{Reflexão sobre a experiência do ateliê didático e formação online}

Segundo nossos depoentes, os ateliês que conduzimos até o momento - cinco turmas de professores em dois anos - provocaram mudanças profundas, tanto do ponto de vista profissional, como pessoal, pois, segundo afirma Nóvoa (2002), o professor antes de ser profissional é uma pessoa. Decerto que os professores também têm críticas ao processo, dentre as quais se destacam as críticas à própria formação online, segundo eles, em suas avaliações, por problemas de domínio das tecnologias, desconhecimento do ambiente moodle e superposição de tarefas. Temos nos dedicado a reconsiderar, a partir de suas falas, a condução do módulo a distância. O que observamos, contudo, é que a tarefa dos diários segue célere, como atividade gratificante para aqueles que aderem à mesma, em grande número. Na última turma que trabalhamos a adesão foi de quase a totalidade dos integrantes do ateliê.

Uma das saídas encontradas foi a oferta de oficinas temáticas que fazem parte do programa de formação Forped - e dentre elas a mais 
procurada: a oficina Moodle. Um ponto positivo a considerar é que vários professores já referem o moodle como ambiente virtual de aprendizagem (AVA) adotado em suas práxis pedagógicas e trazem avaliações muito coerentes, como a possibilidade de melhor organização do processo didático, de depósito de tarefas dos estudantes e sistematização do processo da aferição dos resultados.

Desta maneira, observa-se que os docentes estão ainda presos a uma concepção instrumentalizadora do AVA e, ainda, distantes de uma visão de trabalho colaborativo e criativo diante das inúmeras possibilidades oferecidas pelo ambiente online. Todos integrados à essa cibercultura como praticantes culturais, entretanto, com uma consciência que paulatinamente vem sendo construída.

Observamos que nos fóruns - assim como nos chats — há professores que se destacam nos diálogos empreendidos pela qualidade das informações e reflexões postas, mas não são todos. Dos trabalhos em que provocamos a interação - a construção e ressignificação de planos de ensino; mapas mentais e de mapas conceituais; as discussões em torno dos estudos de caso ou de questões-problemas levantados - tivemos uma participação efetiva de, praticamente, $40 \%$ dos docentes que se inserem nos diálogos conduzidos pelas formadoras e trazem colaborações críticas e pertinentes. Os demais se limitam à postagem das tarefas. Há muito estrada pela frente.

A experiência do ateliê didático, nas suas modalidade presencial e a distância, nos têm demonstrado o quanto um trabalho calcado na vivência sensorial dos conhecimentos, na sua apreensão sensível e inteligível, na compreensão crítica e no compartilhamento de ideias, valores e atitudes, reverberam nas práxis pedagógicas dos professores cursistas e em nossa práxis. Como um verdadeiro dispositivo de formação e de pesquisa-formação, os ateliês didáticos têm possibilitado, enfim, a partir de um trabalho pedagógico sensível e crítico, e de pesquisa, reflexão, sobre a itinerância formativa de cada um, a transformação da práxis pedagógica dos professores envolvidos nesta importante ação. 
Por fim, pode-se afirmar que o Ateliê Didático se revelou em um dispositivo para alterar e ser alterado pela práxis dos sujeitos em formação, conforme depreendido dos diários de formação produzidos e analisados, que tratara das implicações e demandas dos docentes para com a própria formatividade, suas implicações com a docência, com saberes didáticos-pedagógicos e com implicações com o estudante, validando a formação em serviço como processo formativo significativo.

\section{Referências}

ALMEIDA, M. I. DE; PIMENTA, S. G. Pedagogia universitária: Valorizando o ensino e a docência na universidade. Revista Portuguesa de Educação, v. 27, n. 2, p. 7-31, 2014. Disponível em: <http://www.scielo.mec.pt/pdf/rpe/v27n2/ v27n2a02.pdf >. Acesso em: 12 fev. 2018.

ALTHAUS, M. T. M. Docência universitária: saberes e cenários formativos. Ponta Grossa: Todapalavra, 2016.

BARBIER, R. A pesquisa-ação. Brasília: Liber Livro, 2004.

BARBOSA, J. G., HESS, R. O diário de pesquisa: o estudante universitário e o seu diário de pesquisa. Brasília: Liber Livro, 2010.

BARDIN, L. Análise de conteúdo. São Paulo: Edições 70, 2011.

BEHRENS, M. A. Docência universitária num paradigma da complexidade: possibilidades de formação continuada no stricto sensu. Rev. Diálogo Educ., Curitiba. v. 10, n. 29, p. 27-44, 2010. Disponível em: <https://periodicos.pucpr.br/index. php/dialogoeducacional/ article/view/3046/2974>. Acesso em: 12 de fev. 2018.

BRASIL. Lei no 9.394, de 20 de dezembro de 1996. Estabelece as diretrizes e bases da educação nacional. Brasília, DF, 1996. Disponível em: http://www.planalto.gov.br/ccivil_03/LEIS/L9394.htm>. Acesso em: 10 fev. de 2018. 
BRASIL, Ministério da Educação. Diretrizes Curriculares dos Cursos de Graduação. Brasília, DF. [@2013]. Disponível em: <http://portal.mec.gov.br/component/content/article?id=12991>. Acesso em: 10 fev. 2018.

CUNHA, M. I. Trajetórias e lugares da formação do docente da educação superior: do compromisso individual à responsabilidade institucional. Reunião Anual da ANPED, 32, Caxambu, 2009. In: Anais... Caxambu: ANPED, 2009.

CUNHA, M. I. Impasses contemporâneos para a pedagogia universitária no Brasil: Implicações para os currículos e a prática pedagógica. In: LEITE, C. (Org.) Sentidos da Pedagogia no Ensino Superior, Porto: CIIE/Livpsic, 2010. p. 67-71.

D’ÁVILA, C. M. Docência na educação superior: labirintos e saídas na construção da profissionalidade docente. In: D’ÁVILA, C. M.; VEIGA, I. P. A. (Org.). Profissão docente na educação superior. Curitiba: CRV, 2013. p. 19-34.

D’ÁVILA, C. M. Razão e sensibilidade na docência universitária. Em aberto, Brasília, v. 29, n. 97, p. 103 - 118, set/dez 2016.

D’ÁVILA, C. M. Educação como processo de iniciação: por uma didática raciovitalista no contexto da pós-modernidade: entrevista com Michel Maffesoli. In: Revista Diálogo Educacional, Curitiba, v. 17, n. 54, p. 1401-1417, jul./set. 2017.

GUERRA, D. M. de J. Reflexões sobre a exteriorização das experiências formativas via diários online em contextos multirrefenciais de pesquisa/formação. In: SANTOS. E. Diário online: dispositivo multirreferencial de pesquisa formação na cibercultura. Portugal: WhiteBooks, 2014.

HONORÉ B. Para una teoria de la formacion. Madrid: Narcea, 1980.

JOSSO, M. C. Experiências de vida e formação. São Paulo: Cortez, 2004.

LEITE, C.; RAMOS, K. Questões da formação pedagógica-didáctica na sua relação com a profissionalidade docente universitária. In: LEITE, C. (Org.) Sentidos da Pedagogia no Ensino Superior. Porto: CIIE/Livpsic, 2010. p. 29-43. 
LEITE, C.; RAMOS, K. Formação para a docência universitária: Uma reflexão sobre o desafio de humanizar a cultura científica. Revista Portuguesa de Educação, v. 25, n. 1, p. 7-27, 2012. Disponível em: <http://www.scielo.gpeari.mctes.pt/pdf/ rpe/v25n1/v25n1a02.pdf>. Acesso em: 10 fev. 2018.

MADEIRA, A. V. Processos Formativos de docentes universitários. In: COLÓQUIO, 11, C. LUSO-BRASILEIRO, 7 E C. LUSO-AFRO-BRASILEIRO SOBRE QUESTÕES CURRICULARES, 1, Braga, set. 2014: atas..., Braga: Universidade do Minho. IE/ CIEd. p. 679-685, 2014. Disponível em: <http://repositorium.sdum.uminho.pt/ handle/1822/30984>. Acesso em: 10 fev. 2018.

MACEDO, R. S. Compreender/mediar a formação: o fundante da educação. Brasília: Líber Livro, 2010.

MACEDO, R. S. Atos de currículo formação em ato? para compreender, entretecer e problematizar currículo e formação. Ilhéus: Editus, 2011.

MACEDO, R. S. Atos de currículo e autonomia pedagógica: O socioconstrucionismo curricular em perspectiva. Petrópolis, RJ: Vozes, 2013.

MAFFESOLI, M. Éloge de la raison sensible. Paris: Editora La Table Ronde, 2005.

NÓVOA, A. Formação de professores e trabalho pedagógico. Lisboa, Educa: 2002.

OLIVEIRA, V. F. de A. produção de sentidos e aprendizagens no espaço da prática educativa: potencializando inovações no ensino superior. In: LEITE C. (Org.) Sentidos da Pedagogia no Ensino Superior. Porto: CIIE/Livpsic, 2010. p. 141-150.

PIMENTA, S. G.; ANASTASIOU, L. G. C. Docência no Ensino Superior. 4. ed. São Paulo: Cortez, 2010.

SANTOS, E.; WEBER, A. Diários online, cibercultura e pesquisa-formação multirreferencial. EDUECE, Livro 1, s/d. Disponível em: http://www.uece.br/ endipe2014/ebooks/livro1/205-\%20DI\%C3\%81RIOS\%20ONLINE,\%20 CIBERCULTURA\%20E\% 20PESQUISA-FORMA\%C3\% 87\%C3\%830\% 20 MULTIRREFERENCIAL.pdf. Acesso em: 09 fev. 2018. 
SANTOS, E.; WEBER, A. Educação e cibercultura: aprendizagem ubíqua no currículo da disciplina didática. In: Revista Diálogo Educacional, Curitiba, v. 13, n. 38, p. 285-303, jan./abr. 2013.

VASCONCELOS, M. L. M. C. Contribuindo para a formação de professores universitários: relatos de experiências, p. 77-94. In: M. Masetto (org.). Docência na Universidade. Campinas: Papirus, 1998.

Recibido: 30/01/2018

Received: 01/30/2018

Recibido: 30/01/2018

Aprobado: 20/02/2018 Approved: 02/20/2018 Aprobado: 20/02/2018 